\title{
Interaction Between Ferrite Recrystallization and Austenite Formation in Dual-Phase Steel Manufacture
}

\author{
BHARATH BANDI, JOOST VAN KREVEL, and PRAKASH SRIRANGAM
}

\begin{abstract}
In this publication, the effect of heating rate on microstructural evolution of manganese segregated cold reduced dual phase steels is systematically studied for different inter-critical temperatures and holding times. At slow heating rate, completion of ferrite recrystallization before austenite formation led to the preferential formation of austenite on the ferrite grain boundaries leading to a necklace austenite (now martensite) morphology. The slower austenite formation kinetics has been attributed to longer diffusion paths dictated by larger ferrite grain sizes. In medium heating rate condition, microstructure before austenite formation had partially recrystallized ferrite and partially spheroidized cementite. Rapid austenite growth occurred along the rolling direction in carbon-rich cementite regions and dislocation-rich recovered ferrite regions. The presence of partially recrystallized ferrite grains restricted the austenite growth in the normal direction and therefore enabled the formation of thin martensite bands parallel to the rolling direction. At fast heating rate, the microstructure before austenite formation predominately contained un-recrystallized ferrite and un-spheroidized cementite and therefore enabled faster austenite formation kinetics. Thicker martensite bands are formed at fast heating rates due to the absence of recrystallized grains, thereby, enabling the growth of austenite in all directions with a higher preference to the rolling direction.
\end{abstract}

https://doi.org/10.1007/s11661-022-06597-2

(C) The Author(s) 2022

\section{INTRODUCTION}

AMONG the various advanced high strength steels (AHSS), dual phase (DP) steel grades are extensively used for body in white (BIW) vehicle components ${ }^{[1,2]}$ due to their excellent mechanical properties, easy processing route and relatively low alloying costs. ${ }^{[3,4]}$ DP steel's microstructure typically consists of soft ferrite and hard martensite phases with optional bainite and/or retained austenite in it. The presence of both softer and harder phases give these steels an optimal combination of ductility and strength, and therefore makes it an ideal light weight-high strength material. The manufacturing route of this steel consists of heating and holding the initial cold rolled material into the inter-critical annealing region (between $\mathrm{A}_{\mathrm{cl}}$ and $\mathrm{A}_{\mathrm{c} 3}$ ), and followed by quenching such that austenite formed at high

BHARATH BANDI, and PRAKASH SRIRANGAM are with the Warwick Manufacturing Group (WMG), University of Warwick, Coventry, CV4 7AL, UK. Contact e-mail: p.srirangam@warwick.ac.uk JOOST VAN KREVEL is with the Tata Steel, Research and Development, 3H36, PO box 10000, 1970 CA, IJmuiden, The Netherlands.

Manuscript submitted August 27, 2021; accepted January 8, 2022.

Article published online February 4, 2022 temperature transforms to martensite and occasionally bainite at room temperature. ${ }^{[5]}$ The mechanical properties of these steel grades are fully dependent on the volume fractions, morphologies, grain sizes, texture and solute concentration ${ }^{[6-8]}$, etc. of the ferrite/martensite/ bainite phases, which are in turn directly controlled by the various microstructural characteristics of the parent austenite phase. ${ }^{[5,9]}$ It should also be noted that the parent austenite phase and its formation mechanism is also crucial in the manufacturing of other AHSS steels such as medium Mn steels, transformation induced plasticity (TRIP) steels, carbide free bainite steels, and Quench partitioned steels.

In this regard, a considerable amount of research is being done to understand the formation of parent austenite phase during the inter-critical annealing step. ${ }^{[10-14]}$ For instance, Speich et al. proposed that the austenite formation in the hot rolled steels (HR) occurs in three consecutive steps, where firstly pearlite colonies rapidly transform to austenite. Secondly austenite slowly grows into the ferrite grains, which is generally controlled by carbon diffusion. Finally equilibrium between phases is established by manganese enrichment of austenite. ${ }^{[14]}$ However, this austenite formation mechanism is not applicable to cold reduced material (CR) which is most commonly used for production of these steels. This is because of the fact that, unlike HR 
steels, the shape of the ferrite grains and the pearlite colonies are strongly deformed during cold reduction. ${ }^{[15]}$ Due to this the ferrite grain boundary area not only increases significantly, but also is clustered with fragmented cementite particles. ${ }^{[16]}$ As a result, additional high temperature mechanisms such as annihilation of defects through ferrite recovery, ferrite recrystallization and grain growth, play a role during the heating step of $\mathrm{CR}$ material. ${ }^{[17,18]}$ Generally these processes occur below the start temperature of austenite formation $\left(A_{c 1}\right) \cdot{ }^{[18,19]}$ However, to fulfill the ever rising demand for higher strength materials (while maintaining formability), addition of precipitate forming elements like vanadium, titanium, molybdenum and niobium and/or increase in the amount of substitutional alloying elements like manganese, chromium, silicon is becoming a common practice in steel manufacture ${ }^{[20-23]}$ In addition to increasing the strength, these alloying elements retard the high temperature processes, especially ferrite recovery, recrystallization and grain growth, by either precipitate pinning action and/or solute drag effect, thereby, shifting these processes into the temperature range of austenite formation. ${ }^{[21]}$ Moreover, the use of ultrafast heating during continuous annealing can become a promising advancement to the present annealing lines, as it has the potential to decrease the furnace length and thereby substantially increase the energy efficiency. ${ }^{[24,25]}$ However, the employment of high heating rates automatically decreases the time available for the progression of these high temperature processes, thereby, shifting their progress to temperature above $A_{c 1}$ temperature. ${ }^{[24,26]}$ Therefore, the synergetic effect of increase in solute content and the use of high heating rates enable these processes, especially ferrite recrystallization, cementite spheroidization and austenite formation, to occur simultaneously during the heating step of DP steel manufacture.

Excellent studies have been published in the last decade to understand the effect of these concurrent mechanisms on the microstructural evolution of DP steels. ${ }^{[5,27-33]}$ In these studies, very high heating rates are employed to achieve the coupling between these processes, but the extent of overlap at the chosen heating rates was not considered prior to the heat treatments. ${ }^{[21,28,30,34]}$ Moreover, the results obtained from these studies are found to be varying in terms of the final microstructural features. For instance, some studies reported that an increase in heating rate leads to a randomly distributed fine austenite and thereby gives desirable mechanical properties. ${ }^{[35-37]}$ However, other studies reported that the overlap of these high temperature processes resulted in coarse martensite bands. ${ }^{[5,27,28,30,38]}$ Some studies proposed that a complete lack of austenite formation at unrecrystallised ferrite is responsible for banding, ${ }^{[27,39,40]}$ while other studies supported the formation of austenite in unrecrystallised ferrite is the main reason for the development of banded morphology. ${ }^{[28,30]}$ In addition, segregation of solute elements (commonly seen with manganese $\mathrm{e}^{[41]}$ in industrial production) and its effect during the overlap of high temperature mechanisms is generally overlooked in the published literature. This is very critical to understand because manganese segregation not only influences the austenite formation process but also has profound influence on the ferrite recrystallization process. ${ }^{[30]}$

Therefore, in this work, to clarify the ambiguity in the literature, microstructural evolution is systematically studied at various inter-critical temperatures and percentages of overlap in a cold reduced manganese segregated low carbon steel. Special emphasis has been given to the effect of $\mathrm{Mn}$ segregation on the mechanisms of microstructure evolution at the various percentages of overlap.

\section{EXPERIMENTAL PROCEDURE}

The present work was carried out on a 50 pct CR steel with an initial microstructure of ferrite-pearlite. The chemical composition is shown in Table I. The equilibrium austenite start $\left(\mathrm{A}_{\mathrm{e} 1}\right)$ and finish $\left(\mathrm{A}_{\mathrm{e} 3}\right)$ temperatures are calculated using ThermoCalc $2019 \mathrm{~b}$ and were found to be $668{ }^{\circ} \mathrm{C}$ and $830{ }^{\circ} \mathrm{C}$, respectively. The as-received HR steel with $2 \mathrm{~mm}$ thickness was further cold reduced to $1 \mathrm{~mm}$ thickness using Hille-Müller cold-rolling mill. A modified Johnson-Mehl-Avrami-Kolmogorov (JMAK) model was developed for this study to generate heating rates required to produce a predefined amount of overlap to occur between ferrite recrystallization and austenite formation. ${ }^{[42]}$ Based upon the model predictions, heating rates of $0.2{ }^{\circ} \mathrm{C} / \mathrm{s}, 7{ }^{\circ} \mathrm{C} / \mathrm{s}, 50.5^{\circ} \mathrm{C} / \mathrm{s}$ and $51{ }^{\circ} \mathrm{C} / \mathrm{s}$, with corresponding $1,67,88$, and 99 percentages of respective overlaps, were used in this study. This enabled to understand the microstructural evolution of DP steels at various percentages of overlap.

Heat treatments were done on rectangular samples of 10x4 $\mathrm{mm}^{2}$ dimensions and $100 \times 15 \mathrm{~mm}^{2}$ using a Bähr Dilatometer $805 \mathrm{~A} / \mathrm{D}$ and a Gleeble 3180, respectively. An S-type thermocouple is used for the Dilatometry tests $\left(0.2,7\right.$, and $\left.50.5^{\circ} \mathrm{C} / \mathrm{s}\right)$ and a K-type thermocouple is used for Gleeble tests $\left(511^{\circ} \mathrm{C} / \mathrm{s}\right)$. For Gleeble tests copper jaws are used to achieve better temperature control. Using the selected heating rates, the samples were heated to wide range of inter-critical annealing (IA) temperatures and held for holding times ranging from 0 to 900 seconds. Helium gas was used to quench the samples below the martensite start temperature $\left(\mathrm{M}_{\mathrm{s}}\right)$ with a rate of $-150{ }^{\circ} \mathrm{C} / \mathrm{s}$.

For microstructural analysis, samples were mounted and polished on the plane perpendicular to transverse direction using the standard metallographic procedures. After etching with 2 pct Nital, microstructural images and elemental scans were taken using a FEG JEOL 7800F-SEM equipped with secondary electron detector and energy dispersive X-ray spectroscopy (EDX) detector. All the microstructures reported in this study are taken from center or near to center location of the thickness of the samples. The martensite volume fractions from the quenched samples were measured using the point counting method in accordance with ASTM E562-11. ${ }^{[43]}$ Grain size and aspect ratio measurements were calculated using line intercept method according to ASTM E112-12. ${ }^{[44]}$ To track the progress of ferrite 
recrystallization and austenite formation, micro-hardness measurements were done on all the heat-treated samples using Wilson ${ }^{\circledR}$ UH4750 Universal Hardness Tester at a load of $2 \mathrm{Kg}$ and dwell time of 10 seconds. To reveal the misorientation profile (relative to first point) in the ferrite grains, Electron back scattered diffraction (EBSD) was done using Aztec and HKL Channel 5 software (Oxford instruments, UK).

\section{RESULTS}

\section{A. As-Received Cold Rolled Microstructure}

Figures 1(a) through (c) shows the cold rolled steel microstructure with its corresponding EDX scans. It can be seen that both ferrite grains and pearlite colonies are deformed and elongated along the rolling direction. However, ferrite grains are more elongated than pearlite colonies due to its inherent softness. In some parts, the fragmented cementite particles were found to be aligned

Table I. Chemical Composition (Weight Percent) of the Steel Used in This Study

\begin{tabular}{lccccc}
\hline Element & $\mathrm{C}$ & $\mathrm{Mn}$ & $\mathrm{Si}$ & $\mathrm{V}$ & $\mathrm{Fe}$ \\
\hline Wt Pct & 0.14 & 2.1 & 0.37 & 0.06 & bal. \\
\hline
\end{tabular}
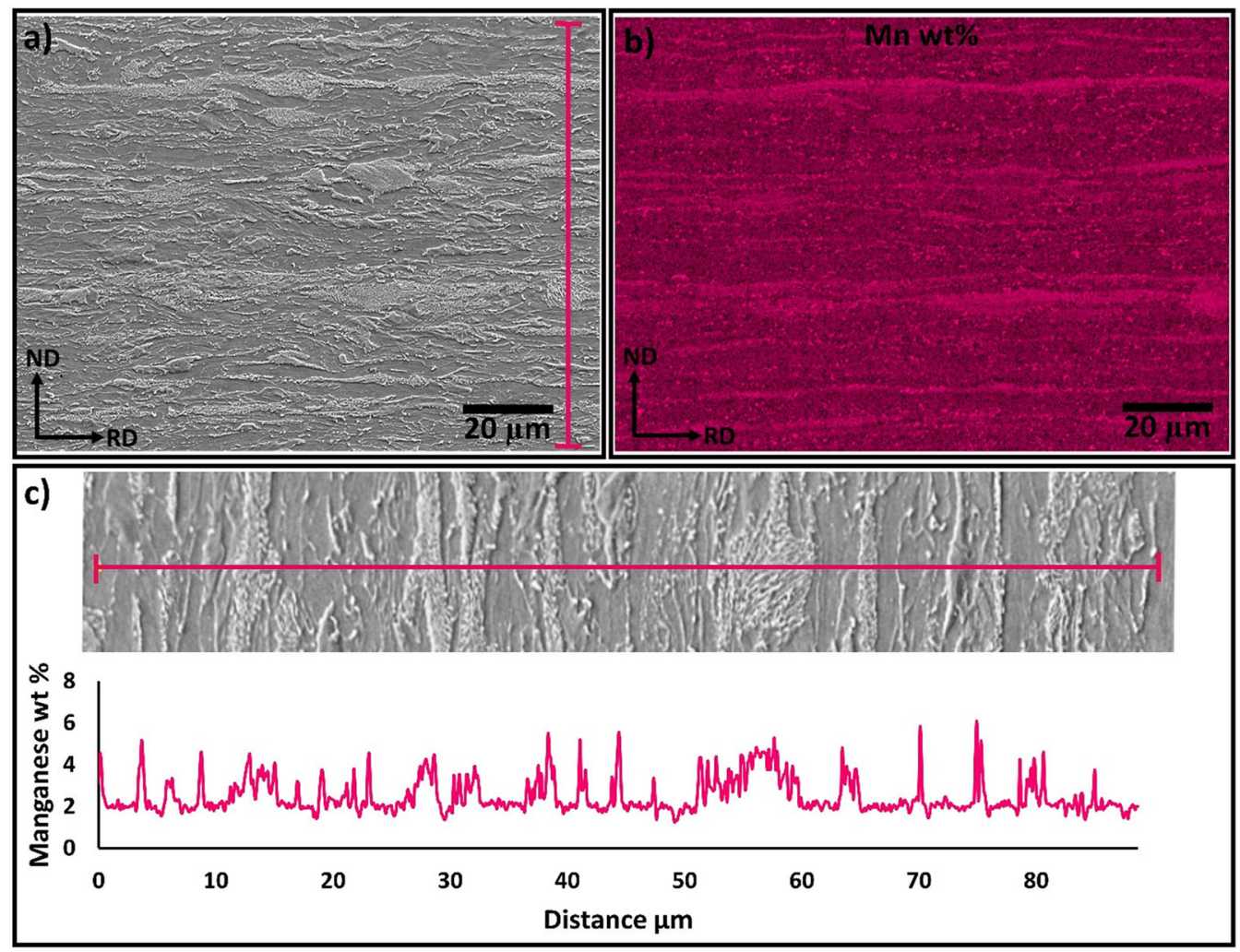

Fig. 1-(a) Microstructure of 50 pct CR steel, $(b)$ corresponding Mn EDX map and $(c)$ Quantitative EDX line scan showing the Mn concentration (wt pct) profile across the pearlite bands. near the elongated ferrite grain boundaries. The volume fraction of pearlite was found to be $21 \pm 2$ pct. Figure $1(\mathrm{~b})$ reveals that the majority of pearlite overlaps with the high manganese concentrated bands. To know the exact concentration profile, quantitative EDX line scans were measured, as shown in Figure 1(c). The banded pearlitic region was found to have 2 to 3 times higher manganese concentration than the ferritic region. This solute segregation is caused due to the solubility difference of solute elements in the liquid and the solid steel. ${ }^{[45]}$ Therefore, during solidification, continuous rejection of solute occurs, leading to a through gauge concentration gradient. Although, the partition coefficient of $\mathrm{Mn}(0.71)$ is high when compared to other solute atoms in this alloy, it is still highly segregated because of its high concentration (2.1 wt pct). Moreover, the lower diffusivity $\left(10^{-26} \mathrm{~m}^{2} / \mathrm{s}\right)$ of $\mathrm{Mn}$ allows the segregation to persist even after hot- and cold-rolling stages. ${ }^{[30]}$

\section{B. Effect of Heating Rate at Low IA Temperature}

Figures 2(a) and (b) represents the variation in martensite fraction at $730{ }^{\circ} \mathrm{C}$ with respect to increasing heating rates and holding times. At shorter or no holding times, an increase in heating rate from 0.2 to 511 ${ }^{\circ} \mathrm{C} / \mathrm{s}$ significantly decreased the martensite fraction (Figure 2(b), holding time 0 second). However, as the holding time increased, this behavior reversed, showing a higher martensite fraction at higher heating rates. This can be explained by the slow austenite formation 

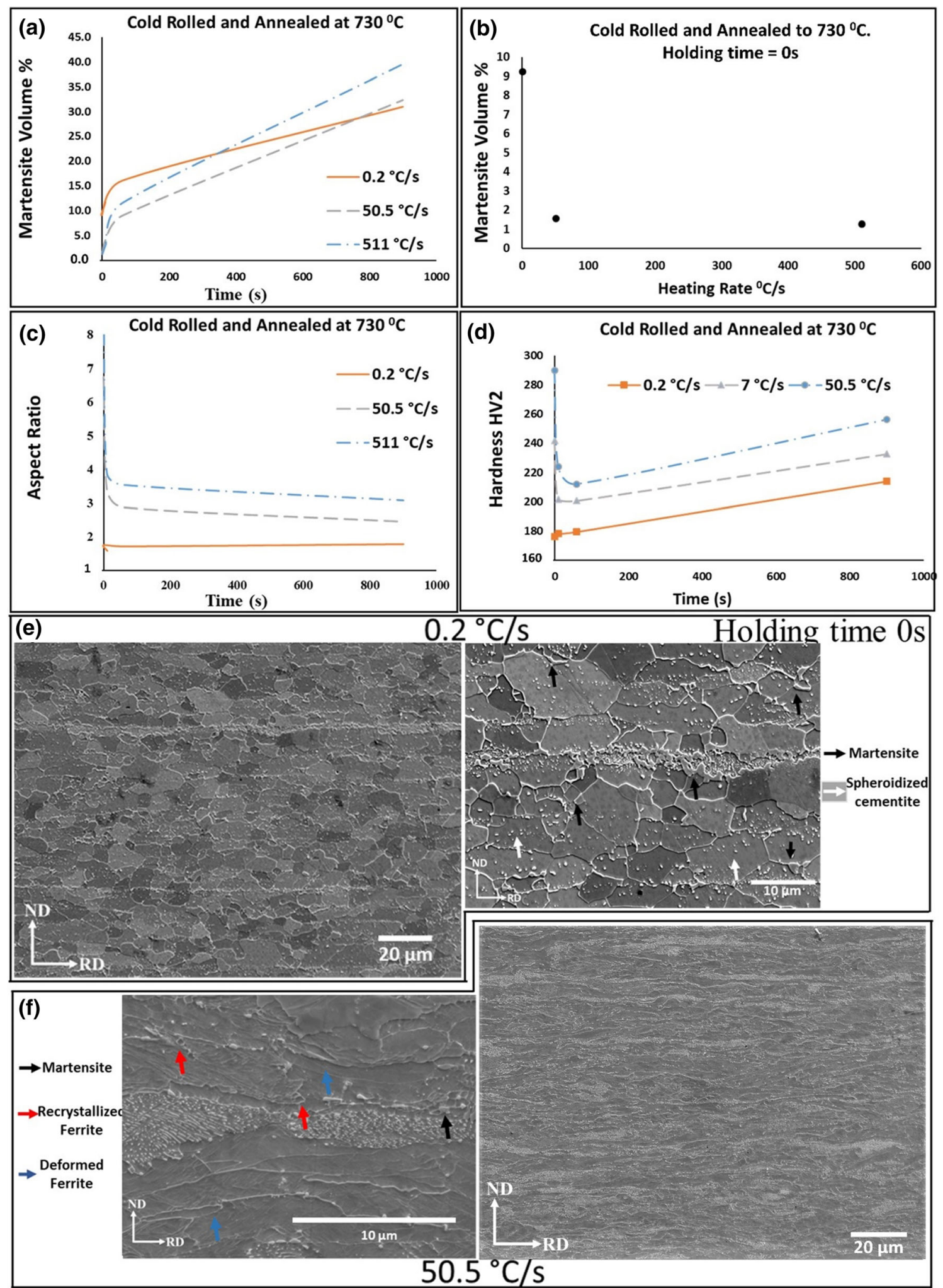

Fig. 2- $(a$ to $d$ ) Effect of heating rate on (a) and (b) Martensite volume percentage, (c) Ferrite grain aspect ratio and (d) Micro-Vicker's hardness at $730{ }^{\circ} \mathrm{C} ;(e)$ and $(f)$ : SEM microstructural images of the samples annealed at $7300^{\circ} \mathrm{C}(0 \mathrm{~s})$ at heating rates of $(\mathrm{e}) 0.2{ }^{\circ} \mathrm{C} / \mathrm{s}$ and $(\mathrm{f})$ $50.5^{\circ} \mathrm{C} / \mathrm{s}$, respectively.

kinetics and/or requirement of high incubation time at lower IA temperatures. ${ }^{[17]}$ Figure 2(c) shows the dependency of ferrite grain aspect ratio on increasing heating rates and holding times. Aspect ratio (AR) is related to the recrystallization process, where a higher aspect ratio represents less progress in recrystallization process. ${ }^{[27]} \mathrm{It}$ 

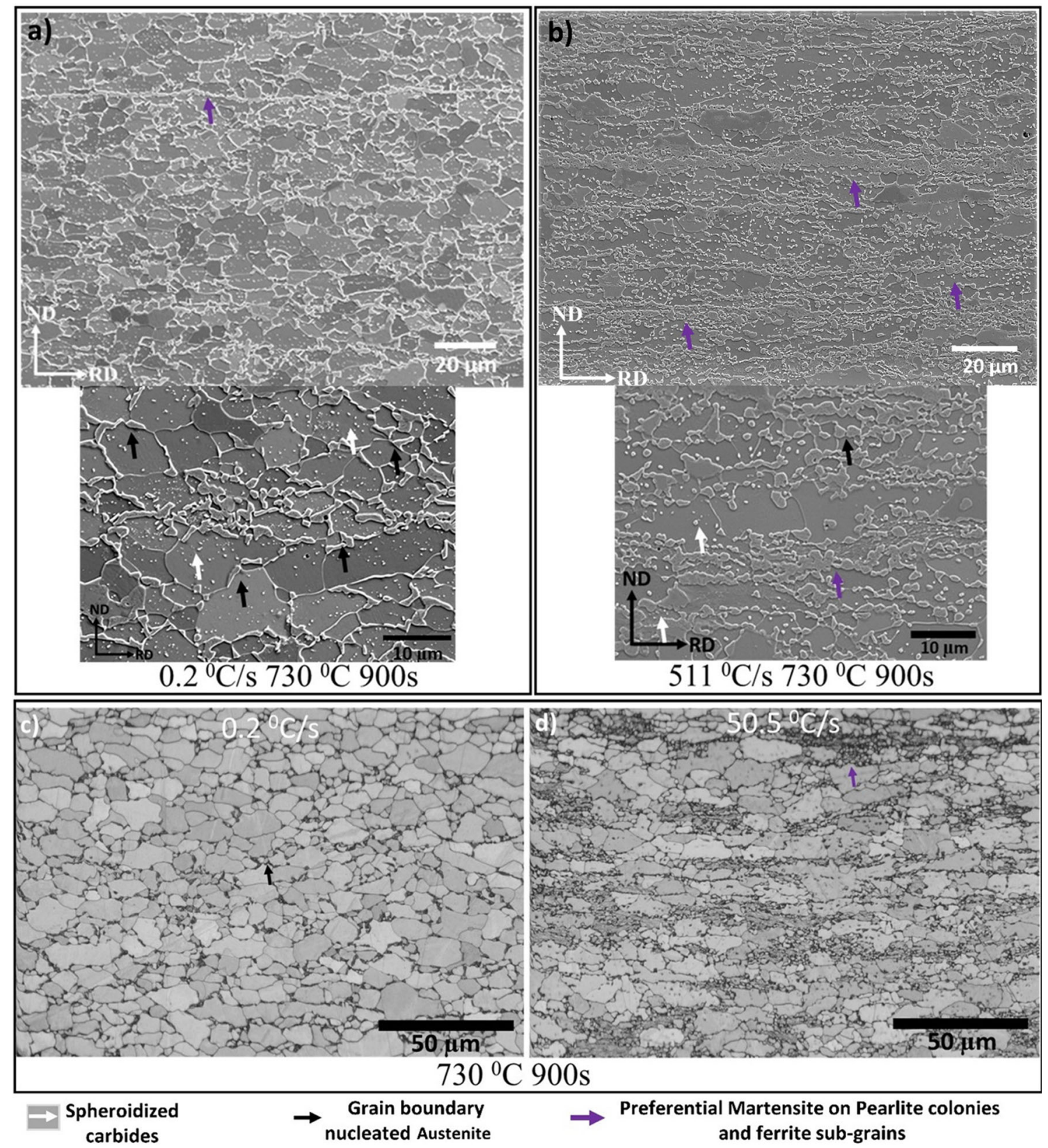

Fig. 3- (a) and (b) Microstructure of the samples annealed at $730{ }^{\circ} \mathrm{C}$ for $900 \mathrm{~s}$ with heating rates of (a) $0.2{ }^{\circ} \mathrm{C} / \mathrm{s}$ and (b) $511{ }^{\circ} \mathrm{C} / \mathrm{s}$; $(c)$ and $(d)$ : EBSD band contrast images of samples annealed at $730{ }^{\circ} \mathrm{C}$ for $900 \mathrm{~s}$ with heating rates of (c) $0.2{ }^{\circ} \mathrm{C} / \mathrm{s}$ and (d) $50.5^{\circ} \mathrm{C} / \mathrm{s}$, respectively.

was found that the AR is relatively high for higher heating rates for all the holding times. For lower heating rate $\left(0.2^{\circ} \mathrm{C} / \mathrm{s}\right)$, AR remained almost constant between 1 and 2 , for all holding times. This indicates that the recrystallization was complete below the annealing temperature. However, samples heated with higher rates displayed a significant decrease in the AR during the initial holding times, implying a rapid progress of ferrite recrystallization. Figure 2(d) shows the variation of hardness (HV2) as a function of heating rate and soaking time. The hardness increased continuously with increase in soaking time for the lowest heating rate $\left(0.2^{\circ} \mathrm{C} / \mathrm{s}\right)$ condition, whereas the hardness values first decreased and then increased in high heating rate conditions. The initial decrease in the hardness, observed for higher heating rates, is ascribed to recrystallization prevailing over austenite formation at this low IA temperature.

Figures 2(e) and (f) shows microstructures of cold rolled samples heated with heating rates of $0.2{ }^{\circ} \mathrm{C} / \mathrm{s}$ and $50.5^{\circ} \mathrm{C} / \mathrm{s}$ respectively to $730{ }^{\circ} \mathrm{C}$ and immediately quenched. The microstructure of the sample heated at $0.2{ }^{\circ} \mathrm{C} / \mathrm{s}$ shows polygonal ferrite grains, which is an indication that recrystallization was complete. Further observation shows that the austenite islands (now martensite after quenching) preferentially nucleated on ferrite grain boundaries (mostly triple points). Moreover, at mid width a band of martensite is observed. 

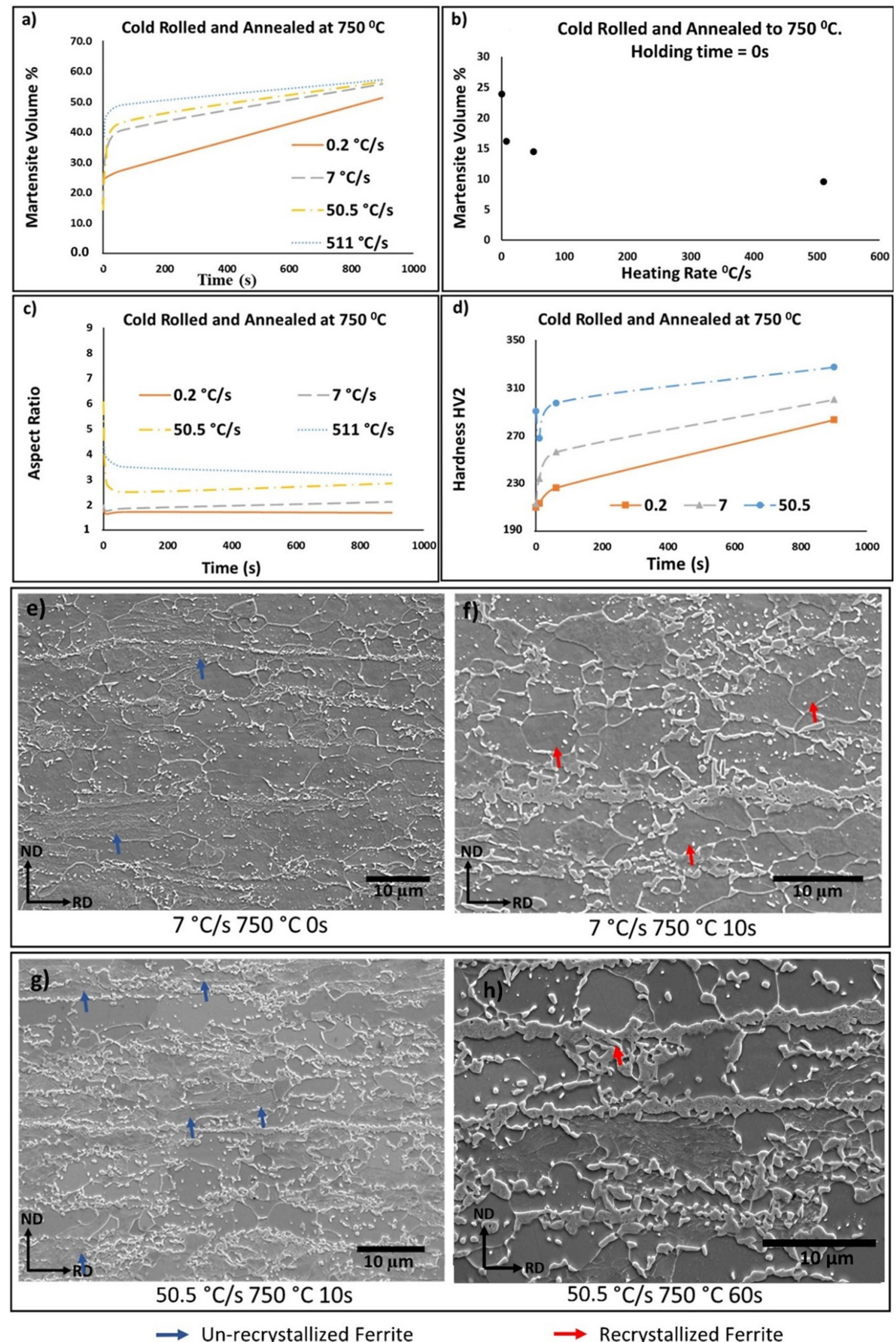

Fig. $4-(a)$ to $(d)$ : Effect of heating rate on (a) and (b) Martensite percentage, (c) Ferrite grain aspect ratio and (d) Micro-Vicker's hardness at $750{ }^{\circ} \mathrm{C} ;(e)$ to $(h)$ : SEM microstructural images of the samples annealed at $750{ }^{\circ} \mathrm{C}$ at heating rates of (e) and (f) $7{ }^{\circ} \mathrm{C} / \mathrm{s}$ for (e) $0 \mathrm{~s}$ and (f) $10 \mathrm{~s}$, and $(g)$ and $(h) 50.5^{\circ} \mathrm{C} / \mathrm{s}$ for $(\mathrm{g}) 10 \mathrm{~s}$ and $(\mathrm{h}) 60 \mathrm{~s}$ 
Additionally, a uniform distribution of spheroidized cementite particles can also be seen throughout the microstructure. In case of the sample heated at higher heating rate $\left(50.5^{\circ} \mathrm{C} / \mathrm{s}\right)$, ferrite recrystallization was incomplete. The microstructure showed a significant amount of fragmented cementite particles (degenerate pearlite) with a minimum quantity of fine spheroidized cementite. A significantly lower martensite fraction was found at this heating rate and martensite was mostly present near prior pearlite islands.

Figures 3(a) and (b) shows the microstructure of the samples annealed at $730{ }^{\circ} \mathrm{C}$ for 900 seconds with heating rates of $0.2{ }^{\circ} \mathrm{C} / \mathrm{s}$ and $511{ }^{\circ} \mathrm{C} / \mathrm{s}$, respectively. For the lower heating rate $\left(0.2{ }^{\circ} \mathrm{C} / \mathrm{s}\right)$, fully recrystallized polygonal ferrite grains with randomly distributed spheroidized cementite particles can be seen. Most martensite islands at lower heating rate have a necklace morphology implying the nucleation and the growth of austenite on recrystallized ferrite grain boundaries. Very few solid martensite bands are observed at the center of the sheets. In contrast to this, the microstructure obtained at $511{ }^{\circ} \mathrm{C} / \mathrm{s}$ predominately consists of martensite bands with a lesser amount of martensite islands in necklace morphology. A significant amount of polygonal ferrite grains can also be seen at this high heating rate for lower IA temperature, indicating that recrystallization preferentially occurs at shorter holding times (see Figures 2(c) and (d)). Spheroidized cementite particles are relatively fine and less frequent and are mostly aligned in the rolling direction. Figures 3(c) and (d) show the EBSD band contrast maps of samples annealed at $730{ }^{\circ} \mathrm{C}$ for 900 seconds with heating rates of $0.2{ }^{\circ} \mathrm{C} / \mathrm{s}$ and $50.5^{\circ} \mathrm{C} / \mathrm{s}$, respectively. It can be seen that the austenite (now martensite) nucleated at $0.2{ }^{\circ} \mathrm{C} / \mathrm{s}$ are randomly distributed on the ferrite grain boundaries and are mostly disconnected from each other, whereas the austenite grains (now martensite) in $50.5^{\circ} \mathrm{C} / \mathrm{s}$ have a band like geometry and are mostly connected.

Figures 4(a) and (b) shows the martensite fraction of the samples heat treated at $750{ }^{\circ} \mathrm{C}$. Similar to $730{ }^{\circ} \mathrm{C}$, the martensite fraction decreased with increase in heating rate for lower holding times (Figure 4(b)). Compared to soaking at lower IA of $730{ }^{\circ} \mathrm{C}$ for higher heating rates, here martensite fraction increased rapidly after very short holding times. This indicates the decrease in incubation time and increase in kinetics of austenite formation at higher temperatures. Martensite fraction is higher for higher heating rates throughout the holding times, however, as the holding time increased the difference between different heating rates was found to be decreased. Figures 4(c) and (d) show the ferrite grain aspect ratio and hardness variation for these annealed samples, respectively. Unlike at $730{ }^{\circ} \mathrm{C}$, ferrite recrystallization was dominant for only shorter holding times, after which austenite formation became the dominant process. Figures 4(e) through (h) show microstructure images, representing the progress of recrystallization for samples annealed at heating rates of $7{ }^{\circ} \mathrm{C} / \mathrm{s}$ and $50.5^{\circ} \mathrm{C} / \mathrm{s}$, respectively. It can be seen that, ferrite was completely recrystallized after 10 seconds for the sample heated with $7^{\circ} \mathrm{C} / \mathrm{s}$, whereas it took almost 60 seconds for the sample heated with a rate of $50.5^{\circ} \mathrm{C} / \mathrm{s}$.
Figures 5(a) through (d) shows microstructures of the samples annealed at $750{ }^{\circ} \mathrm{C}$ for 900 seconds with varying heating rates of $0.2{ }^{\circ} \mathrm{C} / \mathrm{s}, 7{ }^{\circ} \mathrm{C} / \mathrm{s}, 50.5^{\circ} \mathrm{C} / \mathrm{s}$ and $511^{\circ} \mathrm{C} / \mathrm{s}$, respectively. It can be seen that at lower heating rate, martensite is mostly confined to ferrite grain boundaries (black arrow), leading to a necklace morphology. However, a martensite band is visible at the center of the sample thickness (violet arrow), shown in Figure 5(a). With increasing heating rate, austenite (now martensite) increasingly formed as banded morphology as shown in Figures 5(b) through (d). Unlike lower heating rate samples, high magnification images from Figures 5(c) and (d) reveal that martensite also occurred inside the deformed ferrite grains (green arrow) for high heating rates. More interestingly, samples annealed with medium heating rates $\left(7^{\circ} \mathrm{C} / \mathrm{s}\right.$ and $50.5^{\circ} \mathrm{C} / \mathrm{s}$ ) produced a higher number of thinner martensite bands as compared to the ones with higher heating rates $\left(511^{\circ} \mathrm{C} / \mathrm{s}\right)$. The high heating rate $\left(511^{\circ} \mathrm{C} / \mathrm{s}\right)$ samples produced martensite bands which were thicker and fewer in number.

Figures 6(a) and (b) shows microstructural images and Mn EDX line maps of samples annealed at $750{ }^{\circ} \mathrm{C}$ and 100 seconds at heating rates of $0.2{ }^{\circ} \mathrm{C} / \mathrm{s}$ and $50.5^{\circ} \mathrm{C} / \mathrm{s}$, respectively. Both samples show Mn concentration profile with depleted and enriched regions. For slow heating rate sample, Mn concentration was found to be very high at martensite bands (one or two) present at the center of thickness (see Figure 6(a)). However, martensite present at the grain boundaries is not always overlapped with the manganese enriched regions. Moreover, when compared to overall microstructure, the grain size of ferrite grains was found to be very low at the central banded region. For sample heat treated at $50.5^{\circ} \mathrm{C} / \mathrm{s}$, the manganese concentration peaks were found to be overlapped with majority of martensite bands.

Figures 7(a) and (b) shows the EBSD band contrast images and the corresponding recrystallization fraction maps for sample annealed at $745^{\circ} \mathrm{C}$ for 10 seconds with a heating rate of $0.2{ }^{\circ} \mathrm{C} / \mathrm{s}$ and $50.5^{\circ} \mathrm{C} / \mathrm{s}$, respectively. For slow heating rate condition, it can be seen that complete ferrite recrystallisation has occurred. A small fraction of recovered ferrite was also identified (yellow grains) in the recrystallization fraction map. This can be attributed to the formation of martensite islands on the grain boundaries leading to a slightly deformed grain interior. Comparison of Band contrast and recrystallisation fraction maps reveal that the austenite phase (now martensite) has nucleated on the fully recrystallized ferrite grain boundaries, more preferentially at the triple points (black arrow). Figure 7(b) shows that the sample annealed with the heating rate of $50.5^{\circ} \mathrm{C} / \mathrm{s}$ produced a combination of recrystallized (blue), recovered (yellow), and deformed (red) ferrite grains in the microstructure. Unlike slow heating rate condition, austenite (now martensite) preferentially nucleated at dislocation-rich deformed and recovered ferrite grain boundaries and prior pearlitic regions. Figure 8 shows the band contrast EBSD image with representative misorientation profiles of the recrystallized (red line) and recovered ferrite (green line) grains for sample 

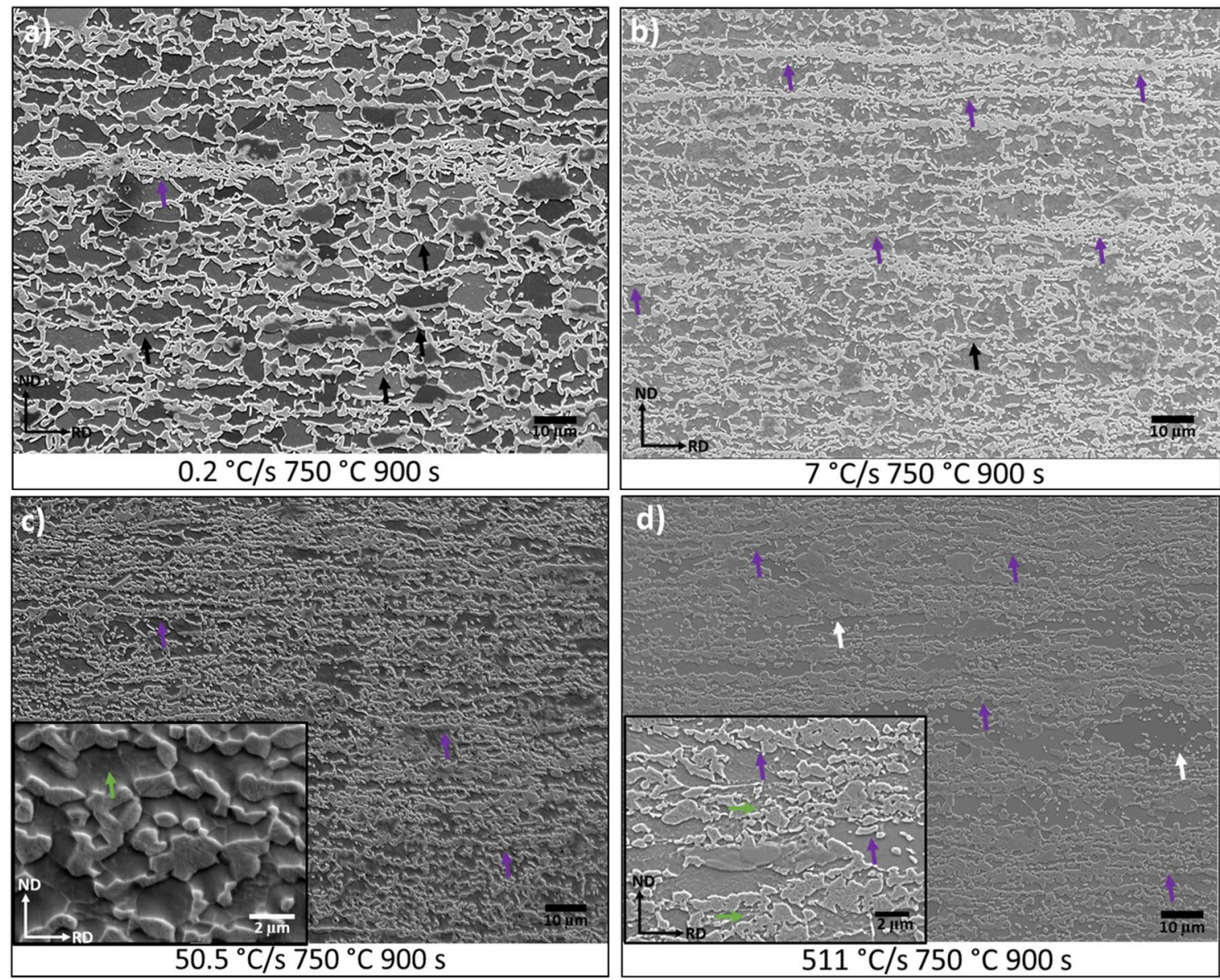

$\rightarrow \begin{gathered}\text { Grain boundary } \\ \text { nucleated Austenite }\end{gathered}$

$\rightarrow$ Martensite Bands

Spheroidized carbides

Austenite grown along recovered structure

Fig. 5-SEM images of the samples annealed at $750{ }^{\circ} \mathrm{C}$ for $900 \mathrm{~s}$ at heating rates of $(a) 0.2{ }^{\circ} \mathrm{C} / \mathrm{s},(b) 7{ }^{\circ} \mathrm{C} / \mathrm{s},(c) 50.5{ }^{\circ} \mathrm{C} / \mathrm{s}$ and $(d) 511^{\circ} \mathrm{C} / \mathrm{s}$.

annealed at $750{ }^{\circ} \mathrm{C}$ for 60 seconds using a heating rate of $50.5^{\circ} \mathrm{C} / \mathrm{s}$. The cumulative misorientation in recovered ferrite is very high compared to recrystallized ferrite due to the presence of high dislocation density and/or dislocation boundaries in the recovered region. It can be seen that the austenite (now martensite) preferentially grown along the dislocation-rich recovery bands which are aligned along the rolling direction. Moreover, from Figure 8(red line), it can be seen that the recrystallized ferrite grains restrict the austenite growth along the normal direction.

\section{Effect of Heating Rate at High IA Temperature}

Figure 9(a) shows the effect of heating rate on martensite percentage at $780{ }^{\circ} \mathrm{C}$. As expected, here also increase in heating rate resulted in an increase in martensite content. The hardness graph (Figure 9(b)) of the sample heat treated at $50.5^{\circ} \mathrm{C} / \mathrm{s}$ shows a steep initial increase in hardness with holding time, signifying that there is no sign of progress of hardness relief related to ferrite recrystallization. Figures 9(c) and (d) show the microstructure of the samples heat treated at $780{ }^{\circ} \mathrm{C}$ for 900 seconds at $50.5^{\circ} \mathrm{C} / \mathrm{s}$ and $511^{\circ} \mathrm{C} / \mathrm{s}$, respectively. Presence of elongated ferrite grains in the microstructure signifies that the recrystallization is not fully complete. It can also be seen that the medium heating rate $\left(50.5^{\circ} \mathrm{C} /\right.$ s) produced thinner bands and higher heating rate $\left(511^{\circ} \mathrm{C} / \mathrm{s}\right)$ produced thicker ones.

\section{DISCUSSION}

\section{A. Microstructure Before Austenite Formation}

In order to rationalize the complexity of microstructure evolution, the annealing parameters in this study are categorized as follows: (1) slow, medium and high heating rates based upon the percentage of overlap between ferrite recrystallization and the austenite formation processes, (2) Low and high inter-critical temperatures and (3) Short and long holding times. To understand the variation in austenite formation with respect to the heating rate employed, it is critical to know the type of microstructure present before the start of austenite formation $\left(\mathrm{A}_{\mathrm{c} 1}\right.$ temperature). Figure 10 schematically represents the initial cold rolled microstructure along with the microstructures obtained just below austenite start temperature for slow, medium and high heating rates. In the cold rolled microstructure, 


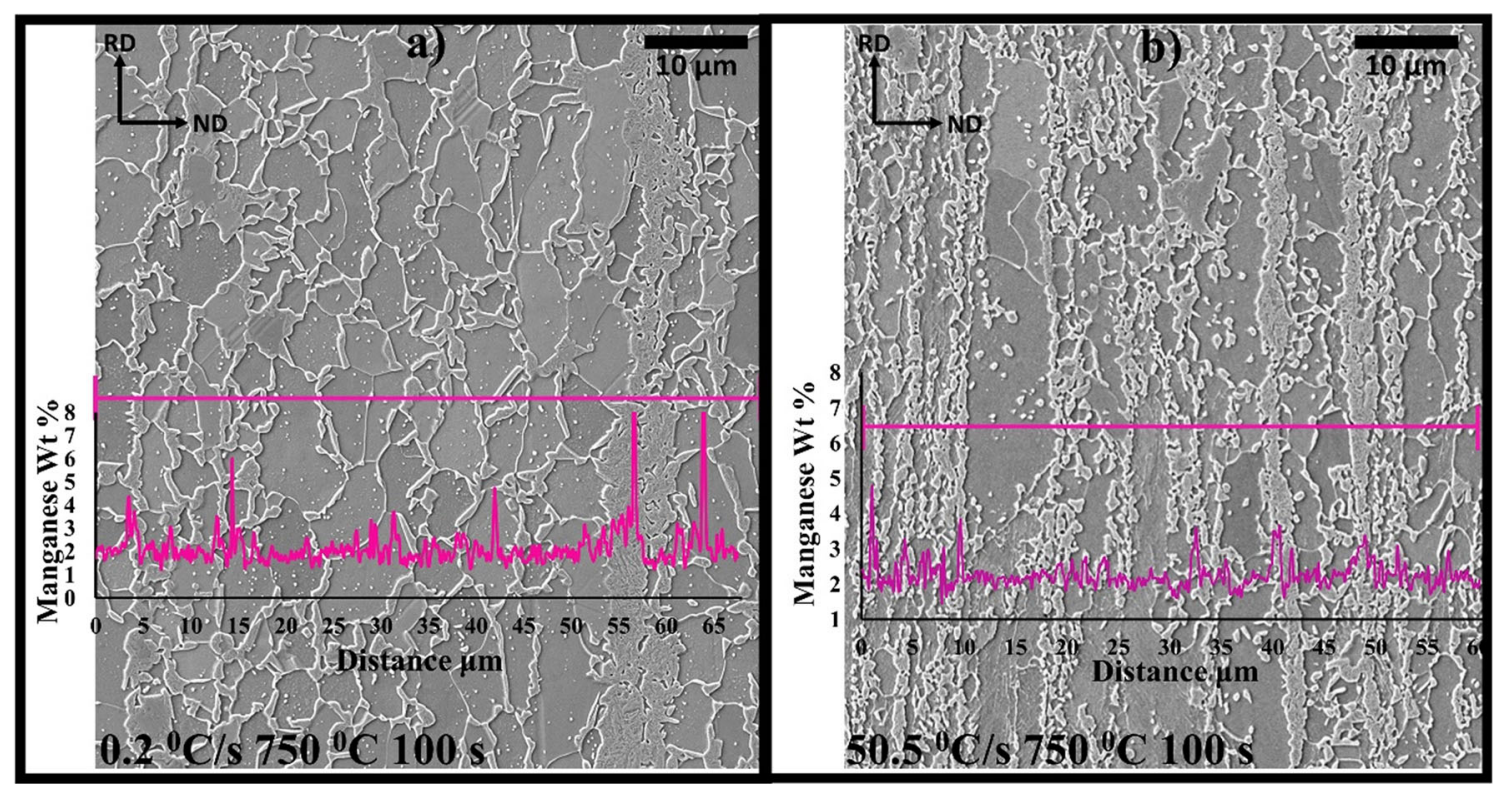

Fig. 6- (a) and (b): SEM microstructural images and Mn concentration profiles of samples annealed at $750{ }^{\circ} \mathrm{C}$ and $100 \mathrm{~s}$ at heating rates of $0.2^{\circ} \mathrm{C} / \mathrm{s}$ and $50.5^{\circ} \mathrm{C} / \mathrm{s}$, respectively.
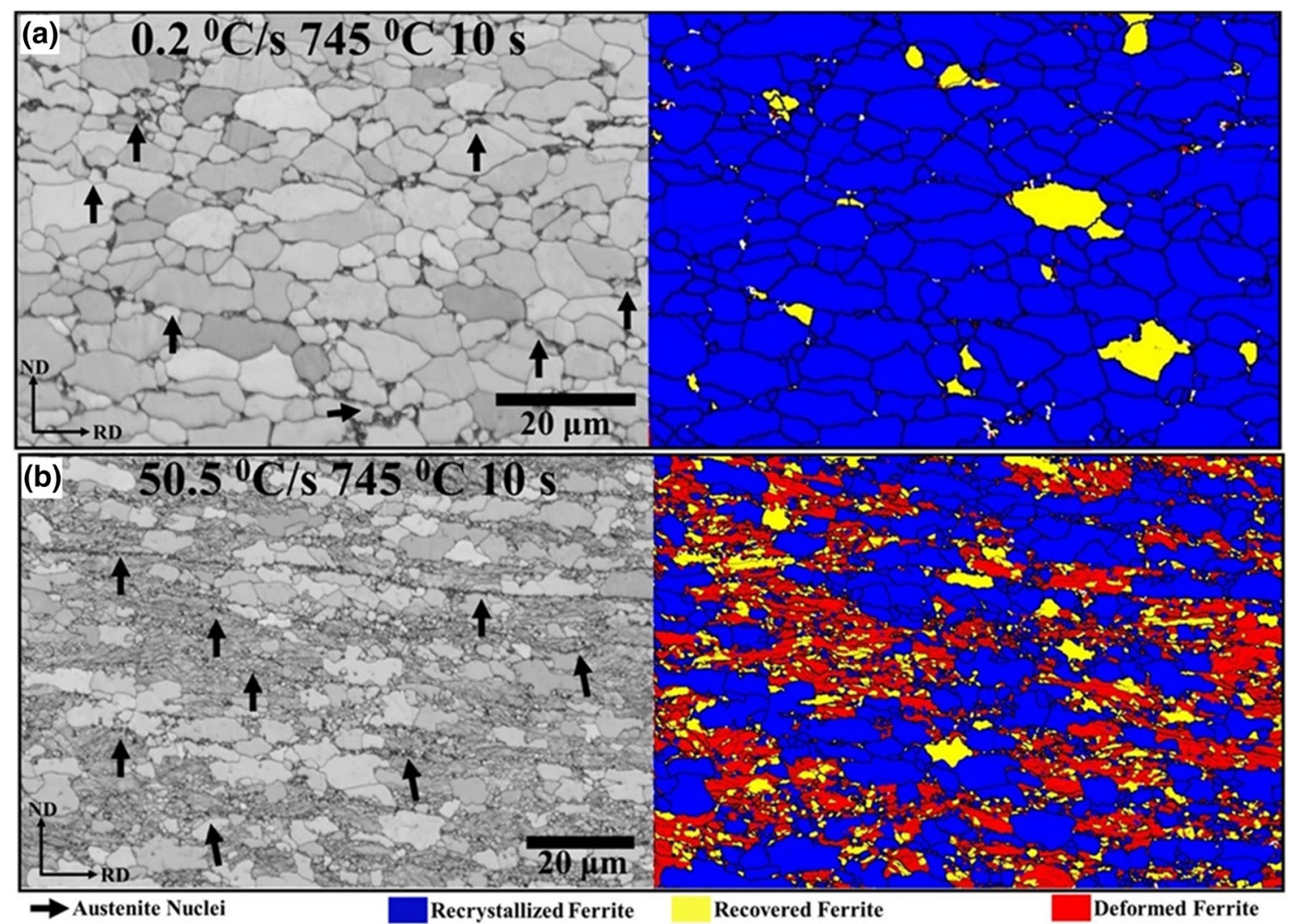

Fig. 7- (a) and (b) EBSD Band contrast images and recrystallization fraction maps of samples heat treated at $745^{\circ} \mathrm{C}$ for $10 \mathrm{~s}$ using heating rates of (a) $0.2{ }^{\circ} \mathrm{C} / \mathrm{s}$ and (b) $50{ }^{\circ} \mathrm{C} / \mathrm{s}$, respectively (Color figure online).

the elongated plain grains represent the deformed ferrite grains, and the patterned grains represent the fractured and partially deformed pearlitic colonies. At slow heating rate, ferrite recrystallization is complete before the onset temperature of austenite formation. Moreover, due to the availability of large time the fragmented cementite lamellae in pearlite colonies get spheroidized while carbon dissolves into solid solution and deposits 

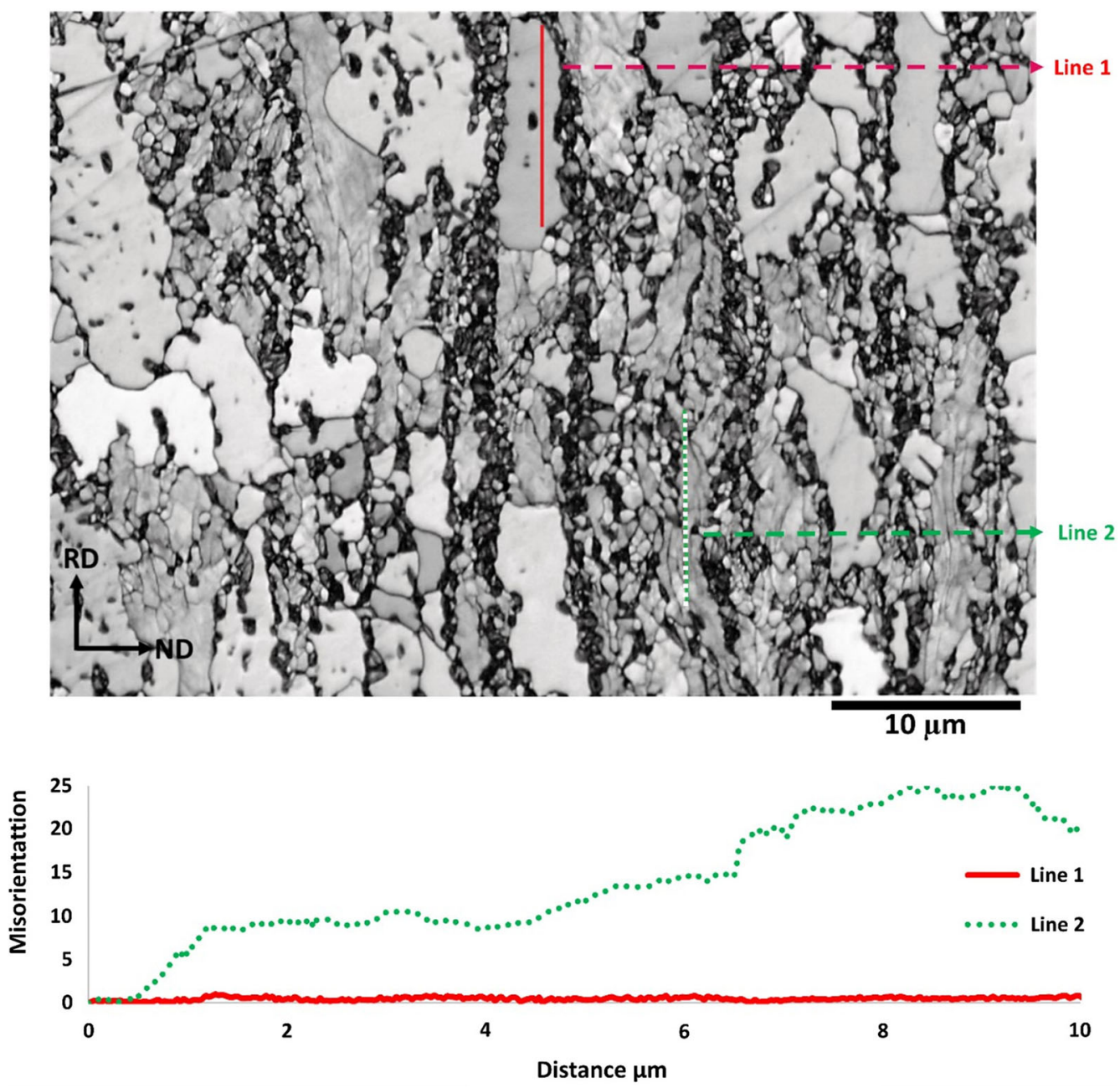

Fig. 8-EBSD band contrast image depicting the misorientation profiles along the recrystallized and the recovered ferrite for the sample annealed at $750{ }^{\circ} \mathrm{C}$ for $60 \mathrm{~s}$ using heating rate of $50.5^{\circ} \mathrm{C} / \mathrm{s}$ (Color figure online).

over the grain boundaries. This can be clearly seen in Figure 2(e) where fully polygonal ferrite grains and completely spheroidized cementite particles are present in sample annealed at slow heating rate $\left(0.2^{\circ} \mathrm{C} / \mathrm{s}\right)$ at low inter-critical temperature $\left(730^{\circ} \mathrm{C}\right)$ and zero holding time. It should also be noted that the deformed ferrite present in the pearlite colonies also recrystallizes. However, as represented visually in Figure 10, the recrystallized grain size in pearlite colonies will be much smaller when compared to the outside one (also see Figure 6(a). This can be explained by the solute drag effect induced by the high manganese concentration in the pearlite colonies on the migrating grain boundaries. ${ }^{[46]}$ Moreover, the presence of high amount of spheroidized cementite particles induce pinning action on the ferrite grain boundaries. Janakiram et al., reported a difference in recrystallisation and grain growth behavior in prior ferritic and pearlitic region by systematically showing different structural changes happening during the annealing process because of the difference in cementite fragments. ${ }^{[47]}$ Due to this, in prior pearlitic regions, ferrite grain growth after recrystallization will be sluggish when compared to the prior deformed ferritic region, leading to a fine ferrite grain size. At medium heating rates, a microstructure of partially recovered and partially recrystallized ferrite will be present before the start of austenite formation. Partial spheroidization of cementite particles is also expected. At very high heating rate, only recovery of ferrite will occur with minimum amount of recrystallization. The pearlite colonies will still be intact as the original cold rolled microstructure.

\section{B. Microstructure Evolution at Slow Heating Rate}

The schematic representation of complete microstructure evolution during slow heating rate condition is shown in Figure 11. As discussed above, ferrite recrystallization and cementite spheroidization precede austenite formation during the slow heating rate condition. It should also be noted that cementite spheroidization simultaneously enriches the grain boundaries with carbon atoms. Granbom et al., reported that in cold deformed steels, rapid spheroidization occurs by simultaneous dissolution and diffusion of carbon solute atoms towards the ferrite grain boundaries. ${ }^{[48]}$ Therefore, due to presence of carbon- rich ferrite grain boundaries and lack of any defect structure, the potential nucleating 

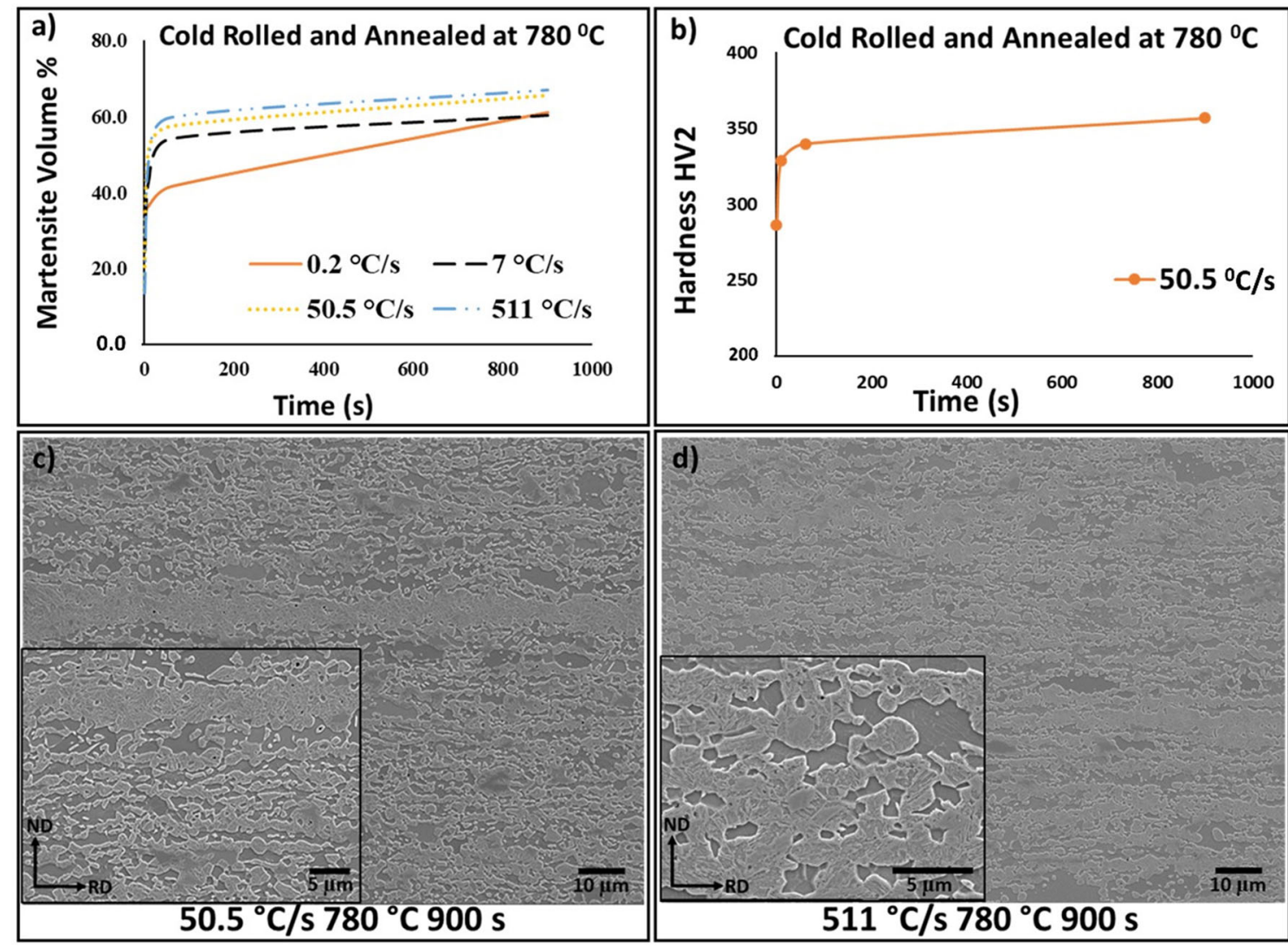

Fig. 9-Effect of heating rate on $(a)$ Martensite percentage, and (b) Micro-Vicker's hardness at $780{ }^{\circ} \mathrm{C} ;(c)$ and $(d)$ SEM microstructural images of the samples annealed at $780{ }^{\circ} \mathrm{C}$ and $900 \mathrm{~s}$ at heating rates of (c) $50.5^{\circ} \mathrm{C} / \mathrm{s}$ and (d) $511^{\circ} \mathrm{C} / \mathrm{s}$, respectively.

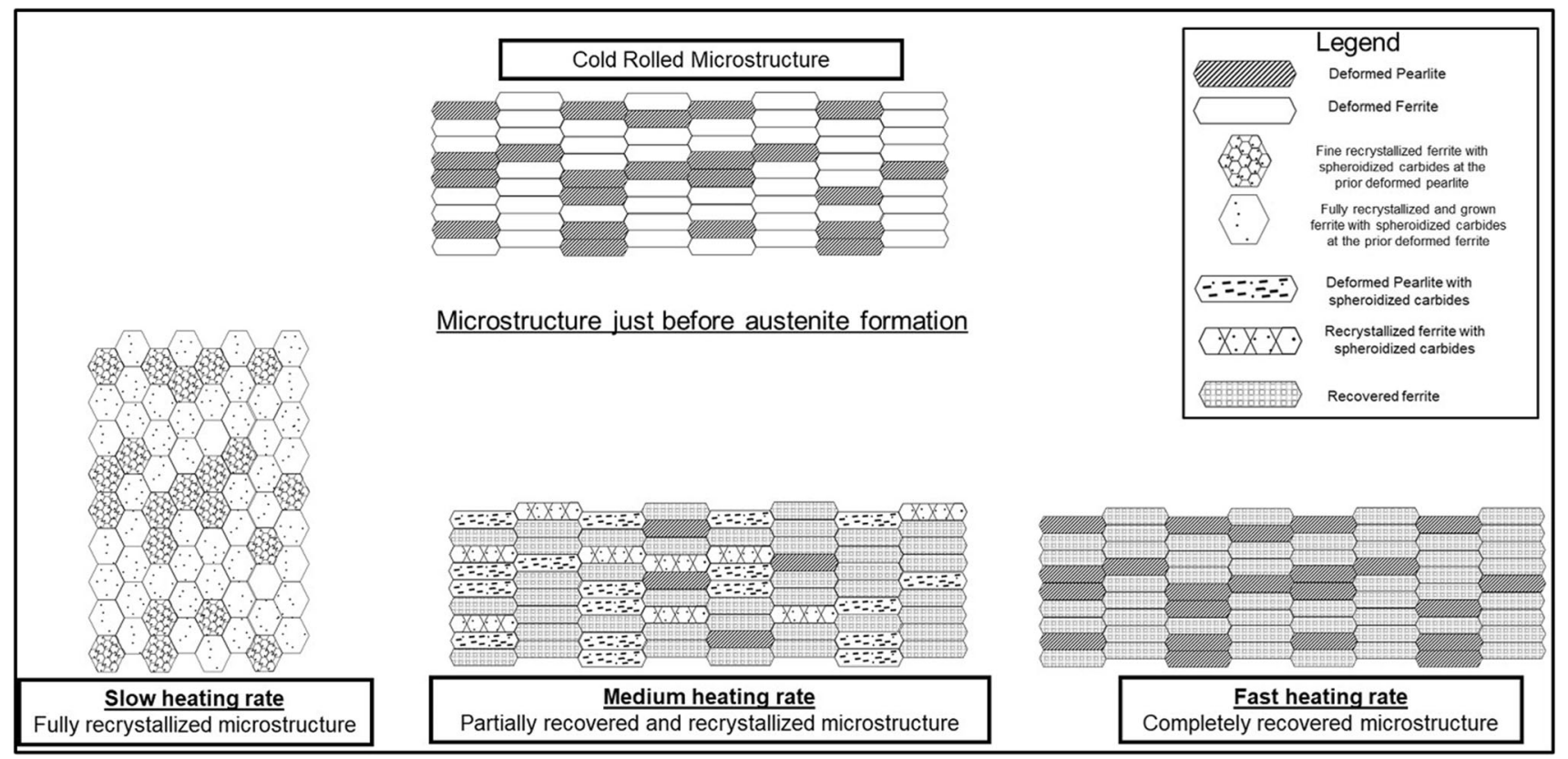

Fig. 10-Schematic representation of cold rolled microstructure along with the microstructure present just before the start of austenite formation.

sites for austenite will be the carbon enriched grain boundaries and more preferentially at triple points. ${ }^{[49]}$ With the increase in annealing temperature and/or soaking time, growth of austenite occurs along the preferential diffusion paths of the solute atoms, in this case grain boundaries. This preferential growth of 


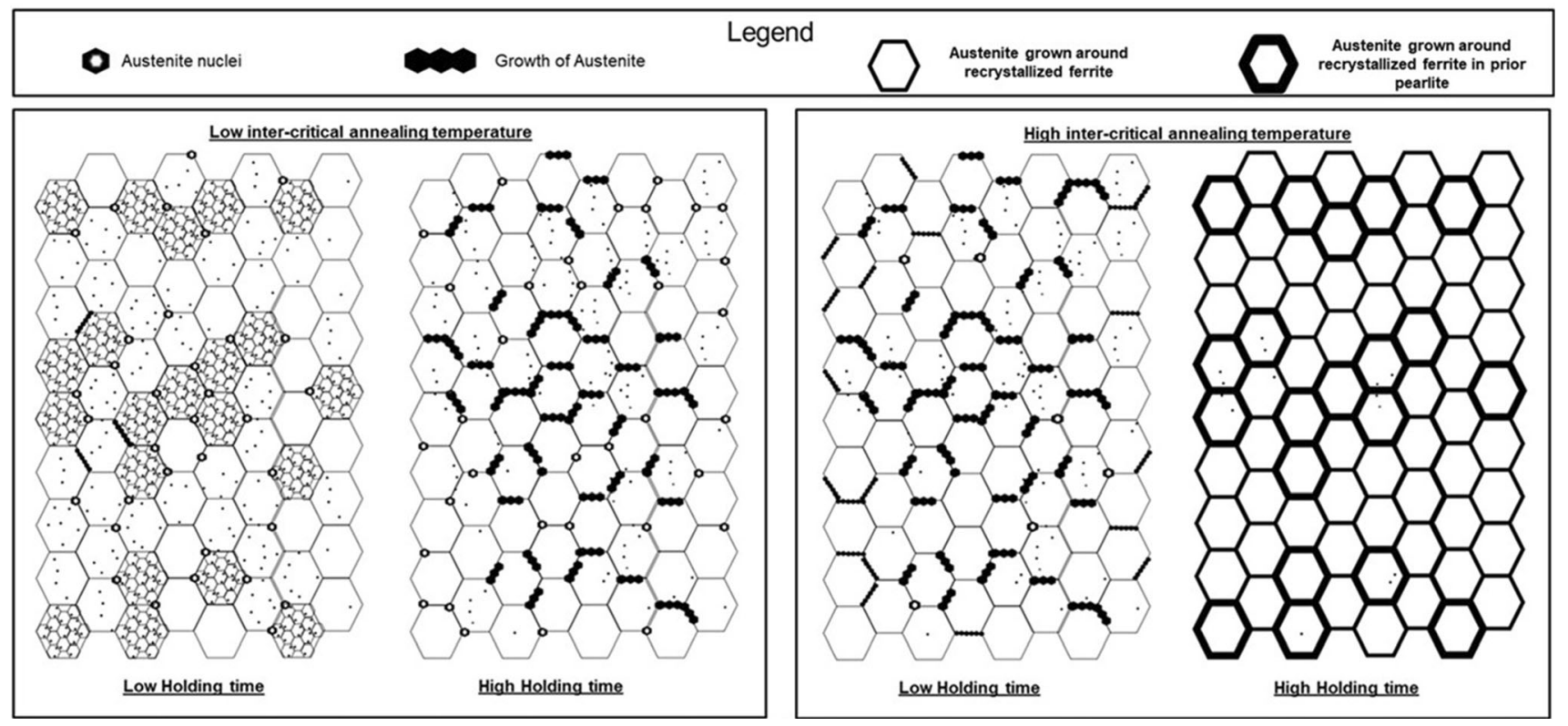

Fig. 11-Schematic representation of microstructure evolution at low heating rate.

austenite on the grain boundaries results in a necklace morphology. However, due to the large grain size of the recrystallized grains, the transport distance along the long grain boundaries increases, leading to a very slow austenite formation. The large distances between the distantly nucleated austenite islands is the main reason for the lower amount of austenite when compared to the higher heating rates. It should be noted that the ferrite grain size in the prior pearlitic region will be relatively small as compared to the prior ferritic region. This is mainly due to the pinning action from the cementite particles and the reduced grain boundary mobility due to the elevated concentration of manganese atoms. ${ }^{[27]}$ Therefore, due to shorter diffusion paths coupled with high manganese concentration, austenite grows rapidly on the boundaries of fine ferrite grains at the pearlitic region. ${ }^{[30]}$ This leads to formation of one or two thick austenite bands as shown in Figure 11. However, these are actually grown on fine ferrite grain boundaries as necklace morphology, as shown in Figure 3(a).

\section{Microstructure Evolution at Medium Heating Rate}

Figure 12(a) shows the schematic representation of microstructure evolution during the medium heating rate condition. The presence of partially recovered ferrite and fragmented cementite represents a weak interaction between ferrite recrystallization, cementite dissolution and austenite formation. Due to the presence of higher amount of fragmented cementite interfaces (especially in prior pearlitic regions) and recovered ferrite grain boundaries, a higher amount of potential nucleating sites are present during this condition, as shown in Figure 7(b). Austenite grows rapidly in the prior pearlitic region due to the presence of readily available carbon in closely spaced cementite particles. It should also be noted that the fragmented cementite lamellae are thermodynamically less stable and degenerate faster than the spheroidized carbides in slow heating rate condition, therefore enable faster growth of austenite. Compared to slow heating rate condition, the presence of partially deformed ferrite with preserved substructure also enables rapid growth. This is because of the availability of faster diffusion paths for the solute atoms in the form of dislocations. ${ }^{[38]}$ Moreover, as shown in Figure 1(c), the presence of high amount of Mn concentration at the fragmented cementite region increases the driving force for further austenite formation due to lower $\mathrm{A}_{\mathrm{e} 1}$ temperature and its associated austenite stability. ${ }^{[30,50]}$ This is evident from Figure 6(b), where majority of $\mathrm{Mn}$ peaks are found to be overlapped with martensite bands. Chbihi et al., and Bos et al., also reported the preferential austenite growth in the $\mathrm{Mn}$ rich regions. ${ }^{[30,51]}$ It is also reported that presence of high $\mathrm{Mn}$ concentration in the prior pearlitic region can retard the progress of ferrite recrystallization process therefore further enabling the austenite formation process. In this condition, the austenite growth is restricted in the normal direction due to the presence of partially recrystallized ferrite grains (Figure 8). The growth of austenite into the recrystallized ferrite grains will be sluggish because of very low carbon concentration in the ferrite grain interiors and lack of any dislocation structure to enable solute diffusion for austenite growth. This growth only occurs after complete saturation of recovered ferrite, i.e., at high temperature and/or long holding time. Therefore, coupled with restriction of growth in normal direction due to partially recrystallized grains and rapid growth of austenite along the former pearlite colonies and the recovered ferrite leads to the formation of large number of thinner martensite bands which are parallel to the rolling direction. 


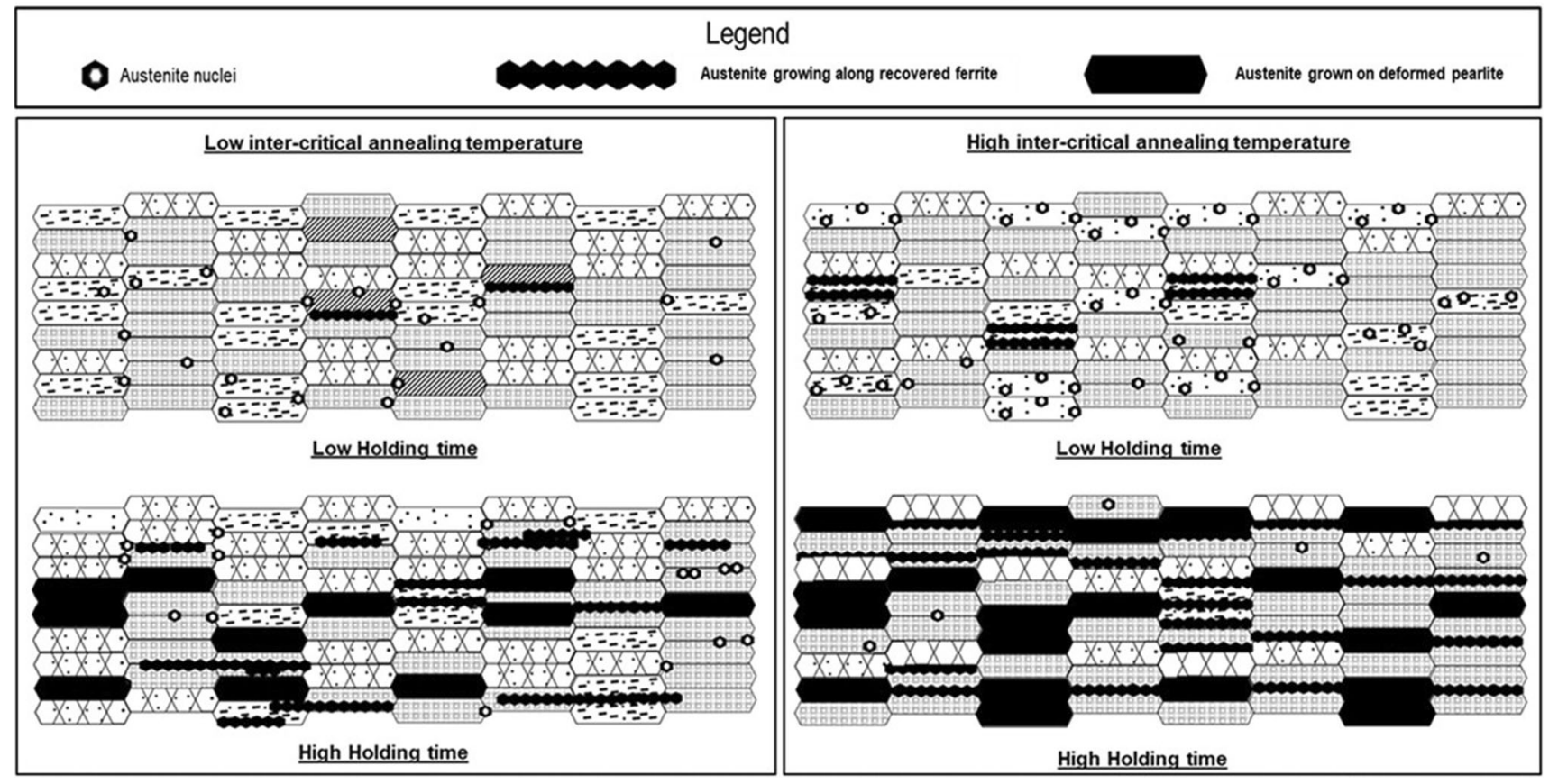

Fig. 12-Schematic representation of microstructure evolution at medium heating rate.

Microstructure evolution at fast heating rate

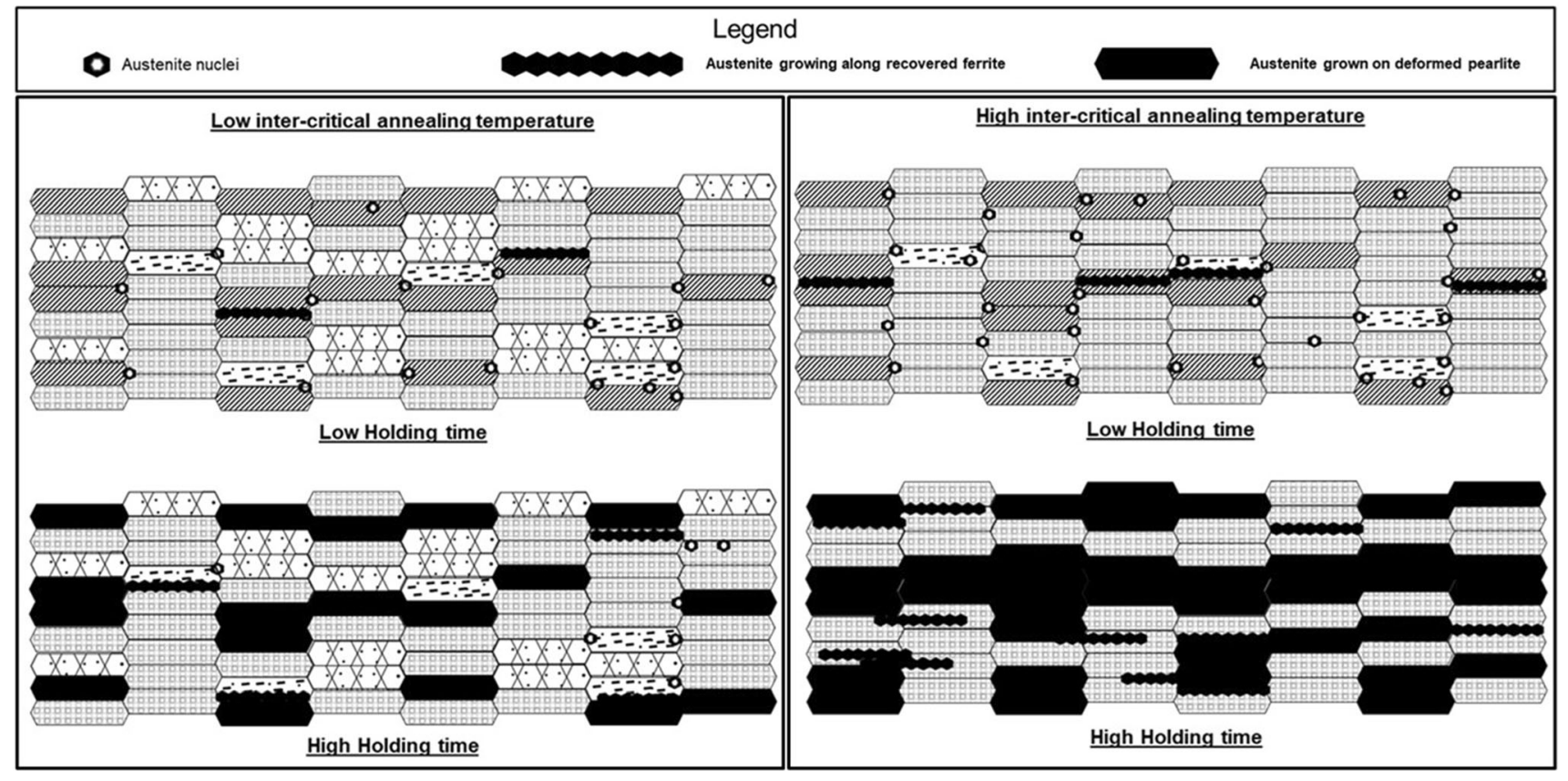

Fig. 13-Schematic representation of microstructure evolution at fast heating rate.

\section{Microstructure Evolution at Fast Heating Rate}

Figure 13 represents the progress of microstructure evolution for the fast-heating rate condition. Very strong overlap between ferrite recrystallization and austenite formation occurs in this case. Due to the large super heat produced by the fast-heating rate, potential austenite nucleating sites will be high. Moreover, the presence of large dislocation boundaries in recovered ferrite creates an excellent diffusion path network for solute atoms (carbon and manganese). Therefore, austenite grows along the directionally aligned 
fragmented pearlite colonies and recovery bands. This leads to a higher percentage of martensite at higher heating rates. It should also be noted that the absence of recrystallized grains in the microstructure makes the growth of austenite unrestricted in all directions. However, the preferential growth direction will be along the prior pearlitic region and recovered ferrite bands, i.e., rolling direction. This leads to the formation of thicker bands when compared to the medium heating rates. Moreover, it is important to note that the driving force for austenite formation is relatively low for lower inter-critical temperature. It is because, at this stage the austenite is thermodynamically not stable enough and its growth over here is controlled by the sluggish diffusion of substitutional elements like manganese and chromium. ${ }^{[52]}$ Therefore, ferrite recrystallization dominates over austenite formation during this stage. This explains the decrease in the hardness during the lower holding times of lower inter-critical temperature. However, complete recrystallization does not occur because of the decrease in driving force for ferrite recrystallization due to ferrite recovery. ${ }^{[53]}$ After enough incubation time, austenite formation picks up quickly along the fragmented pearlite and the remaining recovered ferrite. At higher inter-critical temperature, the driving force for austenite formation is largely due to the reduction in free enthalpy. ${ }^{[18]}$ Additionally, more driving force comes from the decrease in the stored deformation energy by the formation of new austenite nuclei in the recovered ferrite. Due to this, rapid austenitization occur at this stage thereby dominating completely over the ferrite recrystallization process. Moreover, the austenite formation retards the ferrite recrystallization by pinning the ferrite grain boundaries as well thereby inhibiting its migration. The formation of austenite in recovered ferrite also decreases the stored deformation energy thereby decreasing the driving force for the progress of ferrite recrystallization.

\section{CONCLUSIONS}

1. Increase in heating rate decreased the martensite fraction for the lower holding times of the lower inter-critical temperatures. This is because the austenite formation has less driving force at low inter-critical temperatures and requires longer incubation times for its progress. However, for higher holding times, increase in heating rate increased the martensite fraction. Increase in heating rate also changed the martensite islands in the final microstructure from necklace morphology to banded morphology.

2. The slow heating rate condition produced lower martensite fractions due to the absence of fragmented cementite lamella and deformed ferrite during austenite formation. The growth of austenite along the recrystallized grain boundaries was attributed to be slow due to the longer diffusion paths. For higher heating rates, the presence of dislocation substructure and fragmented cementite particles during austenite formation provided excellent carbon diffusion paths, thereby, increased the martensite percentage.

3. For medium heating rate condition, the presence of partially recrystallized ferrite grains restricted the growth in normal direction, thereby, producing thinner martensite bands when compared to higher heating rate condition where the absence of recrystallized grains produced thicker martensite bands.

4. In case of highest heating rate and high inter-critical temperature condition, austenite formation dominated the ferrite recrystallization process. This is attributed to the availability of higher driving force in the form of reduction in both free enthalpy and stored deformation energy.

\section{CONFLICT OF INTEREST}

On behalf of all authors, the corresponding author states that there is no conflict of interest.

\section{OPEN ACCESS}

This article is licensed under a Creative Commons Attribution 4.0 International License, which permits use, sharing, adaptation, distribution and reproduction in any medium or format, as long as you give appropriate credit to the original author(s) and the source, provide a link to the Creative Commons licence, and indicate if changes were made. The images or other third party material in this article are included in the article's Creative Commons licence, unless indicated otherwise in a credit line to the material. If material is not included in the article's Creative Commons licence and your intended use is not permitted by statutory regulation or exceeds the permitted use, you will need to obtain permission directly from the copyright holder. To view a copy of this licence, visit http://creat ivecommons.org/licenses/by/4.0/.

\section{REFERENCES}

1. B.B. He, M. Wang, L. Liu, and M.X. Huang: Mater. Sci. Technol. (United Kingdom)., 2019, vol. 35, pp. 2109-14.

2. J. Zhao and Z. Jiang: Prog. Mater. Sci., 2018, vol. 94, p. 94.

3. M. Delincé, Y. Bréchet, J.D. Embury, M.G.D. Geers, P.J. Jacques, and T. Pardoen: Acta Mater., 2007, vol. 55, pp. 2337-50.

4. S. Oliver, T.B. Jones, and G. Fourlaris: Mater. Charact., 2007, vol. 58, pp. 390-400

5. H. Azizi-Alizamini, M. Militzer, and W.J. Poole: Metall. Mater. Trans. A., 2011, vol. 42A, pp. 1544-57.

6. L. Schemmann, S. Zaefferer, D. Raabe, F. Friedel, and D. Mattissen: Acta Mater., 2015, vol. 95, pp. 386-98.

7. D. An, S. Il Baik, Q. Ren, M. Jiang, M. Zhu, D. Isheim, B.W. Krakauer, and D.N. Seidman: Mater. Charact., 2020, https://doi. org/10.1016/j.matchar.2020.110207.

8. A. Bag, K.K. Ray, and E.S. Dwarakadasa: Metall. Mater. Trans. A., 2001, vol. 32A, pp. 2207-17. 
9. A. Banis, E.H. Duran, V. Bliznuk, I. Sabirov, R.H. Petrov, and S. Papaefthymiou: Metals (Basel)., 2019, https://doi.org/10.3390/me t9080877.

10. C.I. Garcia and A.J. Deardo: Metall. Trans. A., 1981, vol. 12A, pp. 521-30.

11. W.J. Kaluba, R. Taillard, and J. Foct: Acta Mater., 1998, vol. 46, pp. 5917-27.

12. F.G. Caballero, C. Capdevila, and C.G. De Andrés: J. Mater. Sci., 2002, vol. 37, pp. 3533-40.

13. C. García De Andrés, F.G. Caballero, C. Capdevila, and H.K.D.H. Bhadeshia: Scr. Mater., 1998, vol. 39, pp. 791-96.

14. G.R. Speich, V.A. Demarest, and R.L. Miller: Metall. Trans. A., 1981, vol. 12A, pp. 1419-28.

15. A. Karmakar, M. Ghosh, and D. Chakrabarti: Mater. Sci. Eng. A., 2013, vol. 564, pp. 389-99.

16. D.Z. Yang, E.L. Brown, D.K. Matlock, and G. Krauss: Metall. Trans. A., 1985, vol. 16, pp. 1385-92.

17. N. Peranio, F. Roters, and D. Raabe: Mater. Sci. Forum., 2012, vol. 715-716, pp. 13-22.

18. N. Peranio, Y.J. Li, F. Roters, and D. Raabe: Mater. Sci. Eng. A., 2010, vol. 527, pp. 4161-68.

19. I.A. El-Sesy, H.J. Klaar, and A.H.A. Hussein: Steel Res., 1990, vol. 61, pp. 131-35.

20. C.P. Scott, F. Fazeli, B. Shalchi Amirkhiz, I. Pushkareva, and S.Y.P. Allain: Mater. Sci. Eng. A., 2017, vol. 703, pp. 293-303.

21. M. Bellavoine, M. Dumont, J. Drillet, V. Hébert, and P. Maugis: Metall. Mater. Trans. A., 2018, vol. 49A, pp. 2865-75.

22. F. Perrard and C. Scott: ISIJ Int., 2007, vol. 47, pp. 1168-77.

23. G.H. Zhu, X.H. Zhang, and W.M. Mao: Front. Mater. Sci. China., 2009, vol. 3, pp. 442-46.

24. L. Kestens, A.C.C. Reis, W.J. Kaluba, and Y. Houbaert: Mater. Sci. Forum., 2004, vol. 467-470, pp. 287-92.

25. T. Lolla, G. Cola, B. Narayanan, B. Alexandrov, and S.S. Babu: Mater. Sci. Technol., 2011, vol. 27, pp. 863-75.

26. M. Mazinani and W.J. Poole: Metall. Mater. Trans. A., 2007, vol. 38A, pp. 328-39.

27. J. Huang, W.J. Poole, and M. Militzer: Metall. Mater. Trans. A., 2004, vol. 35A, pp. 3363-75.

28. M. Kulakov, W.J. Poole, and M. Militzer: Metall. Mater. Trans. A., 2013, vol. 44A, pp. 3564-76.

29. C. Philippot, M. Bellavoine, M. Dumont, K. Hoummada, J. Drillet, V. Hebert, and P. Maugis: Metall. Mater. Trans. A., 2018, vol. 49A, pp. 66-77.

30. A. Chbihi, D. Barbier, L. Germain, A. Hazotte, and M. Gouné: $J$. Mater. Sci., 2014, vol. 49, pp. 3608-21.

31. A. Karmakar, M. Mandal, A. Mandal, M. Basiruddin Sk, S. Mukherjee, and D. Chakrabarti: Metall. Mater. Trans. A., 2016, vol. 47A, pp. 268-81.
32. F.M. Castro-Cerda, F. Vercruysse, T.N. Minh, L. Kestens, A. Monsalve, and R. Petrov: Steel Res. Int., 2016, https://doi.org/10. 1002/srin.201600351.

33. P. Roumen, S. Jurij, K. Wlodzimierz, and K. Leo: Mater. Sci. Forum., 2012, vol. 715-716, pp. 661-66.

34. M. Bellavoine, M. Dumont, M. Dehmas, A. Stark, N. Schell, J. Drillet, V. Hébert, and P. Maugis: Mater. Charact., 2019, vol. 154, pp. $20-30$.

35. R. Petrov, F. Hajyakbari, F.R. Saz, J. Sidor, M.J. Santofimia, J. Sietsma, and L. Kestens: Mater. Sci. Forum., 2013, vol. 753, pp. 554-58.

36. H. Azizi-Alizamini, M. Militzer, and W.J. Poole: ISIJ Int., 2011, vol. 51, pp. 958-64.

37. D. De Knijf, A. Puype, C. Föjer, and R. Petrov: Mater. Sci. Eng. A., 2015, vol. 627, pp. 182-90.

38. L.S. Thomas and D.K. Matlock: Metall. Mater. Trans. A., 2018, vol. 49A, pp. 4456-73.

39. C. Zheng and D. Raabe: Acta Mater., 2013, vol. 61, pp. 5504-17.

40. B. Zhu and M. Militzer: Metall. Mater. Trans. A., 2015, vol. 46A, pp. 1073-84.

41. T.F. Majka, D.K. Matlock, and G. Krauss: Metall. Mater. Trans. A., 2002, vol. 33A, pp. 1627-37.

42. B. Bandi, J. van Krevel, N. Aslam, and P. Srirangam: JOM., 2019, vol. 71, pp. 1386-95.

43. ASTM: Practice, 2011, pp. 1-7.

44. A.S.T.M. Standard: ASTM Int., 2012, vol. E112-12, pp. 1-27.

45. A. Ghosh: in Sadhana-Academy Proceedings in Engineering Sciences, vol. 26, 2001, pp. 5-24.

46. H. Hu and S.R. Goodman: Metall. Trans., 1970, vol. 1, pp. 3057-64.

47. S. Janakiram, P.S. Phani, G. Ummethala, S.K. Malladi, J. Gautam, and L.A.I. Kestens: Scr. Mater., 2020, https://doi.org/10.10 16/j.scriptamat.2020.113676.

48. Y. Granbom: Structure and Mechanical Properties of Dual Phase Steels-An Experimental and Theoretical Analysis, 2010.

49. T. Ogawa: Int. J. Mech. Mater. Eng., 2015, https://doi.org/10.11 86/s40712-015-0049-4

50. B. Bandi, J. Van Krevel, S. Nandi, Z. Husain, and P. Srirangam: Mater. Today., 2019, vol. 41, pp. 1030-34.

51. C. Bos, M.G. Mecozzi, D.N. Hanlon, M.P. Aarnts, and J. Sietsma: Metall. Mater. Trans. A., 2011, vol. 42A, pp. 3602-10.

52. E. Navara and R. Harrysson: Scr. Metall., 1984, vol. 18, pp. 605-10.

53. A. Rollett, F. Humphreys, G.S. Rohrer, and M. Hatherly: Recrystallization and Related Annealing Phenomena: Second Edition, 2004.

Publisher's Note Springer Nature remains neutral with regard to jurisdictional claims in published maps and institutional affiliations. 